\title{
Fontes de potássio no crescimento in vitro de plantas de orquídea Cattleya loddigesii
}

\author{
Potassium sources of Cattleya loddigesii plants in vitro growth
}

\author{
Milene Alves de Figueiredo ${ }^{\mathrm{I}}$ Moacir Pasqual ${ }^{\mathrm{II}}$ Aparecida Gomes de Araujo ${ }^{\mathrm{II}}$ \\ Keize Pereira Junqueira ${ }^{\text {III }}$ Flávia Carvalho Santos ${ }^{\mathrm{II}}$ Vantuil Antônio Rodrigues ${ }^{\mathrm{II}}$
}

\begin{abstract}
Plantas de Cattleya loddigesii com 1,0-1,5cm de comprimento, oriundas de sementes germinadas in vitro, foram inoculadas nos tratamentos, os quais consistiram da adição de diferentes concentrações de cloreto e sulfato de potássio (ambos a 0, 125, 250, 375 e 500mg $L^{-1}$ ) ao meio Knudson C, em todas as combinações possivieis, acrescido de $2 \mathrm{~g} L^{-1}$ de carvão ativado e $150 \mathrm{~g} L^{-1}$ de polpa de banana "Nanica". O meio teve seu $\mathrm{pH}$ ajustado para 5,8 $\pm 0,1$ e foi solidificado com $5 \mathrm{~g} \mathrm{~L}^{-1}$ de ágar antes da autoclavagem a $121^{\circ} \mathrm{C}$ por 20 minutos. Após a inoculação, as culturas foram mantidas por 90 dias em sala de crescimento com irradiância em torno de $35 \mu \mathrm{mol} \mathrm{m} \mathrm{m}^{-2}$ $s^{-1}$, temperatura de $25 \pm 1{ }^{\circ} \mathrm{C}$ e fotoperiodo de 16 horas. A combinação de 500mg $\mathrm{L}^{-1}$ de $\mathrm{KCl}$ com $500 \mathrm{mg} \mathrm{L}^{-1}$ de $\mathrm{K}_{2} \mathrm{SO}$ promoveu maior crescimento in vitro em plantas de Cattleya loddigesii, exceto no comprimento de raízes, que se apresentou melhor com 500mg $L^{-1}$ de $\mathrm{KCl}$ na ausência de $\mathrm{K}_{2} \mathrm{SO}_{4}$
\end{abstract}

Palavras-chave: Orchidaceae, cultura de tecidos, cloreto de potássio, sulfato de potássio.

\section{ABSTRACT}

Cattleya loddigesii preceding seedlings (with 1.0 $1.5 \mathrm{~cm}$ ) of in vitro germinated seeds were used as explants. The treatments consisted of the addition of different potassium chloride concentrations $\left(0 ; 125 ; 250 ; 375\right.$ e $\left.500 \mathrm{mg} \mathrm{L}^{-1}\right)$ and potassium sulphate $\left(0 ; 125 ; 250 ; 375\right.$ e $\left.500 \mathrm{mg} \mathrm{L}^{-1}\right)$, in the Knudson $C$ medium, in all possible combinations, an addition of $2 \mathrm{~g} \mathrm{~L}^{-1}$ activated coal, $150 \mathrm{~g} \mathrm{L^{-1 }}$ and banana 'Nanica' pulp. The medium had the $p H$ set to $5.8 \pm 0.1$ and was solidified with agar $5 \mathrm{~g} \mathrm{L^{-1 }}$ before the sterilization at $121^{\circ} \mathrm{C}$ for 20 minutes. After the inoculation, the cultures were maintained in the growth room with irradiancy around $35 \mu \mathrm{mol} \mathrm{m} \mathrm{m}^{-2} \mathrm{~s}^{-1}$ in, $25 \pm 1^{\circ} \mathrm{C}$ temperature and 16-hour photoperiod for 90 days. The combination of $\mathrm{KCl} 500 \mathrm{mg} \mathrm{L^{-1 }}$ with $\mathrm{K}_{2} \mathrm{SO}, 500 \mathrm{mg} \mathrm{L}^{-1}$ promotes good in vitro growth in Cattleya loddigesii seedlings, except length of roots who if comported better with $\mathrm{KCl} 500 \mathrm{mg} \mathrm{L^{-1 }}$ in absence of $\mathrm{K}_{2} \mathrm{SO}_{4}$.

Key words: Orchidaceae, tissue culture, potassium chloride, potassium sulphate.

O cultivo in vitro de células e tecidos tem sido excelente alternativa a ser empregada para a propagação das orquidáceas, pois apresenta vantagens únicas sobre os métodos convencionais de propagação, como multiplicação rápida e obtenção de grande número de plantas com alta qualidade genética e fitossanitária.

Os elementos minerais exigidos em maiores quantidades para o crescimento de plantas são incluídos nos meios nutritivos nas formas de sais inorgânicos, podendo o potássio ser adicionado como componente de suplementos orgânicos. O potássio é absorvido pelas plantas na forma de $\mathrm{K}^{+}$e é usualmente o catiônico mais abundante nas células vegetais. Seu principal papel é o de ativador de numerosas enzimas.

Outro papel proposto para o potássio e que o liga indiretamente à fotossíntese é o de promoção da translocação dos assimilados das folhas. Esses íons são transportados rapidamente através das membranas das células e duas de suas principais funções são regular o pH e o equilíbrio osmótico dentro das células. Neste contexto, possuem um papel similar em tecidos cultivados in vitro, porém os mecanismos usuais de transporte podem não ocorrer. A deficiência de potássio no meio de cultura conduz, segundo alguns autores, à

\footnotetext{
'Departamento de Biologia, Setor de Fisiologia Vegetal, Universidade Federal de Lavras (UFLA), Lavras, MG, Brasil. E-mail: migueiredo@yahoo.com.br. Autor para correspondência.

IDepartamento de Agricultura, UFLA, Lavras, MG, Brasil.

"I'Universidade de Brasília (UNB), Brasília, DF, Brasil.
} 
hiperidricidade e ao decréscimo na taxa de absorção de fosfato (PASQUAL, 2001).

O potássio entra como íon acompanhante do nitrato, fosfato ou, em alguns casos, do cloreto e enxofre (CALDAS et al., 1998). Quando o cloro é o ânion acompanhante, na forma de $\mathrm{KCl}$, eles são absorvidos em quantidades equivalentes ao potássio. Entretanto, quando se utiliza o enxofre como acompanhante, na forma de $\mathrm{K}_{2} \mathrm{SO}_{4}$, tem-se maior ativação de enzimas proteolíticas e síntese de vitaminas.

Pode haver injúrias por sais em plantas ornamentais em concentrações acima de $0,2-0,7 \%$ na solução nutritiva. Em geral, plantas ornamentais que têm alta exigência de nutrientes são menos sensíveis a salinidade (ZEHLER et al., 1986). Esta preocupação levou à realização deste trabalho, que objetiva estudar os efeitos de diferentes concentrações de cloreto e sulfato de potássio no crescimento in vitro de plantas de orquídea Cattleya loddigesii.

Foram utilizadas plantas de orquídea Cattleya loddigesii oriundas de sementes germinadas in vitro, com 1 a $1,5 \mathrm{~cm}$ de comprimento e contendo raízes pequenas $( \pm 0,5 \mathrm{~cm})$. Os tratamentos consistiram da adição de diferentes concentrações de cloreto e sulfato de potássio (ambos a 0, 125, 250, 375 e 500mg $\mathrm{L}^{-1}$ ) ao meio KNUDSON C (1946), em todas as combinações possíveis, acrescido de $2 \mathrm{~g} \mathrm{~L}^{-1}$ de carvão ativado e $150 \mathrm{~g} \mathrm{~L}^{-1}$ de polpa de banana "Nanica".

$\mathrm{O}$ meio teve seu $\mathrm{pH}$ ajustado para 5,8 $\pm 0,1 \mathrm{e}$ foi solidificado com $5 \mathrm{~g} \mathrm{~L}^{-1}$ de ágar antes do processo de autoclavagem a $121^{\circ} \mathrm{C}$ e $1,1 \mathrm{~atm}$, por 20 minutos. Após o resfriamento, os frascos de vidro com capacidade para $250 \mathrm{~cm}^{3}$ e contendo $60 \mathrm{~mL}$ de meio de cultura foram levados à câmara de fluxo laminar, onde foi feita a inoculação das plantas, sob condições assépticas. Após a inoculação, os frascos foram mantidos por 90 dias em sala de crescimento com irradiância em torno de $35 \mu \mathrm{mol} \mathrm{m} \mathrm{m}^{-2}$, temperatura de $25 \pm 1^{\circ} \mathrm{C}$ e fotoperíodo de 16 horas. A seguir, o experimento foi avaliado mediante o número e comprimentos de raízes $(\mathrm{cm})$, altura da parte aérea $(\mathrm{cm})$ e massa seca $(\mathrm{g})$ de plantas.

A análise de variância foi realizada utilizando o procedimento GLM do software estatístico SAS ${ }^{\circledR}$ (SAS, 1990), por meio do método dos quadrados mínimos ponderados pelo inverso das variâncias de cada tratamento, uma vez que estes apresentaram heterogeneidade de variâncias.

Pela análise de variância, verificou-se que houve interação significativa dos fatores para todas as variáveis testadas. Pelo teste F, após realização do desdobramento, verificou-se que as concentrações de $\mathrm{K}_{2} \mathrm{SO}_{4}$ combinadas com $500 \mathrm{mg} \mathrm{L}^{-1}$ de $\mathrm{KCl}$ foram significantes para número de raízes e altura da parte aérea. Os parâmetros comprimento de raízes e massa seca apresentaram significância entre concentrações de $\mathrm{K}_{2} \mathrm{SO}_{4}$ combinadas com 250 e $500 \mathrm{mg} \mathrm{L}^{-1}$ de $\mathrm{KCl}$.

A figura 1A representa o número de raízes em plantas de Cattleya loddigesii nas concentrações estudadas de $\mathrm{K}_{2} \mathrm{SO}_{4}$ e $500 \mathrm{mg} \mathrm{L}^{-1}$ de $\mathrm{KCl}$. Derivando-se a equação, pode-se chegar ao valor de $202,76 \mathrm{mg} \mathrm{L}^{-1} \mathrm{de}$ $\mathrm{K}_{2} \mathrm{SO}_{4}$ como ponto de mínima, ou seja, a partir dessa concentração houve aumento crescente do número de raízes $(4,33)$ até a dose máxima utilizada $\left(500 \mathrm{mg} \mathrm{L}^{-1}\right)$, o que leva a inferir-se que o efeito estimulante do $\mathrm{K}_{2} \mathrm{SO}_{4}$ continuaria em concentrações superiores. $\mathrm{O}$ maior comprimento de raízes $(3,12 \mathrm{~cm})$ foi obtido com $500 \mathrm{mg}$ $\mathrm{L}^{-1}$ de $\mathrm{KCl}$ e na ausência de $\mathrm{K}_{2} \mathrm{SO}_{4}$ (Figura 1B). Já na concentração de $250 \mathrm{mg} \mathrm{L}^{-1}$ de $\mathrm{KCl}$, a melhor dose de $\mathrm{K}_{2} \mathrm{SO}_{4}$ a ser empregada foi $218,87 \mathrm{mg} \mathrm{L}^{-1}$. A partir desse ponto, houve decréscimo no crescimento de raízes. Essa tendência, provavelmente, indica o efeito tóxico do excesso de $\mathrm{K}_{2} \mathrm{SO}_{4}$ na planta.

A absorção de um dado nutriente pode ser influenciada por outro. Por exemplo, a presença do íon $\mathrm{K}^{+}$tem efeito de inibição competitiva entre os íons $\mathrm{Mg}^{+2}$ $\mathrm{e} \mathrm{Ca}^{+2}$ (MALAVOLTA et al. 1997). KANASHIRO (2005) verificou correlação linear entre o aumento nas concentrações de potássio e o consumo de nitrato pelas células, promovendo um maior incremento nas características fitotécnicas em plantas de bromélias.

NUNES et al. (2005), testando concentrações de nitrato de cálcio e cloreto de potássio na micropropagação do porta-enxerto de videira "Kobber", conseguiram maior número de raízes e comprimento mais alto da parte aérea com a utilização de $1.000 \mathrm{mg} \mathrm{L}^{-1}$ de $\mathrm{KCl}$ e $500 \mathrm{mg} \mathrm{L}^{-1}$ de nitrato de cálcio.

A dose de $177,8 \mathrm{mg} \mathrm{L}^{-1}$ de $\mathrm{K}_{2} \mathrm{SO}_{4}$ foi evidenciada como ponto de mínima para altura da parte aérea na concentração de $500 \mathrm{mg} \mathrm{L}^{-1}$ de $\mathrm{KCl}$ (Figura 1C) registrando-se um aumento da variável com a elevação da concentração de $\mathrm{K}_{2} \mathrm{SO}_{4}$ até $500 \mathrm{mg} \mathrm{L}^{-1}$, deduzindose que o efeito estimulante do $\mathrm{K}_{2} \mathrm{SO}_{4}$ poderia continuar em concentrações mais altas. Estes resultados discordam de JUNQUEIRA et al. (2003), que, estudando o crescimento in vitro de crisântemo, obtiveram maior comprimento da parte aérea com baixas concentrações de nitrato de cálcio combinado com altas concentrações de cloreto de potássio (1000 $\left.\mathrm{mg} \mathrm{L}^{-1}\right)$.

Melhores resultados para a variável massa seca de plantas (Figura 1D) foram obtidos com a utilização de $500 \mathrm{mg} \mathrm{L}^{-1}$, tanto de $\mathrm{KCl}$ como de $\mathrm{K}_{2} \mathrm{SO}_{4}$. A concentração de $250 \mathrm{mg} \mathrm{L}^{-1} \mathrm{KCl}$ combinada com a dose de $312 \mathrm{mg} \mathrm{L}^{-1} \mathrm{de}_{2} \mathrm{SO}_{4}$ (ponto de máxima) proporcionou melhores respostas para a variável. A partir desse ponto, houve queda na massa seca de plantas, o que pode ser devido ao efeito tóxico de altas concentrações de sulfato de potássio no meio.

O fator nutricional depende do fluxo de densidade ou da quantidade de nutrientes utilizados 

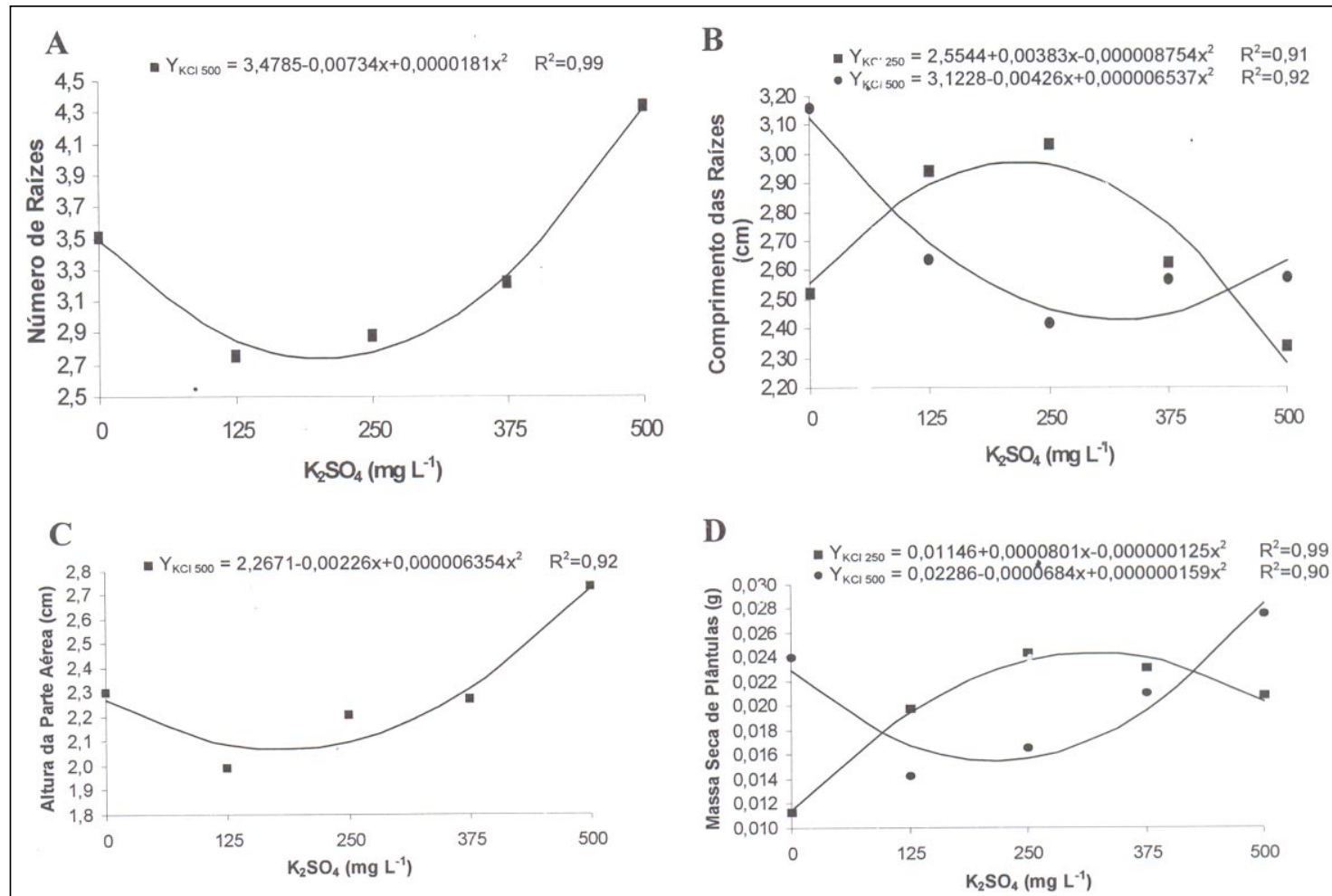

Figura 1 - (A) Número de raízes em diferentes concentrações de $\mathrm{K}_{2} \mathrm{SO}_{4}$ e $500 \mathrm{mg} \mathrm{L}^{-1} \mathrm{KCl}$. (B) Comprimento (cm) de raízes em diferentes concentrações de $\mathrm{K}_{2} \mathrm{SO}_{4}$ e $\mathrm{KCl}$ a 250 e $500 \mathrm{mg} \mathrm{L}^{-1}$. (C) Altura $(\mathrm{cm})$ da parte aérea em diferentes concentrações de $\mathrm{K}_{2} \mathrm{SO}_{4}$ e $500 \mathrm{mg} \mathrm{L}^{-1} \mathrm{KCl}$. (D) Massa seca (g) em diferentes concentrações de $\mathrm{K}_{2} \mathrm{SO}_{4}$ e $\mathrm{KCl}$ a 250 e $500 \mathrm{mg} \mathrm{L}^{-1}$ em plantas de Cattleya loddigesii.

por unidade de tempo e unidade de área. A absorção de nutrientes minerais é afetada pela constituição do meio de cultura, pela composição do tecido da planta e pelo ambiente de cultura (WILLIANS, 1991), fatores que poderiam prognosticar e/ou predizer a adequada composição do meio nutritivo baseada nas análises de tecidos de plantas crescidas in vitro. A combinação de $\mathrm{KCl}$ com $\mathrm{K}_{2} \mathrm{SO}_{4}$, ambos na concentração de $500 \mathrm{mg}$ $\mathrm{L}^{-1}$, promoveu maior crescimento in vitro em plantas de Cattleya loddigesii, exceto no comprimento de raízes, que se apresentou melhor com $500 \mathrm{mg} \mathrm{L}^{-1} \mathrm{de} \mathrm{KCl}$ na ausência de $\mathrm{K}_{2} \mathrm{SO}_{4}$.

\section{REFERÊNCIAS}

CALDAS, L.S. et al. Meios nutritivos. In: TORRES, A.C. et al. Cultura de tecidos e transformação genética de plantas. Brasília: Embrapa-SPI/Embrapa-CNPH, 1998. V.1, p.87-132.

JUNQUEIRA, K.P. et al. Crescimento in vitro de crisântemo: efeito do nitrato de cálcio $\left[\mathrm{Ca}\left(\mathrm{NO}_{3}\right)_{2} \cdot 4 \mathrm{H}_{2} \mathrm{O}\right.$ e cloreto de potássio $(\mathrm{KCl})$. In: CONGRESSO BRASILEIRO DE FLORICULTURA E PLANTAS ORNAMENTAIS, 14., CONGRESSO BRASILEIRO DE CULTURA DE TECIDOS DE PLANTAS, 2003, Lavras. Anais... Lavras: UFLA/FAEPE, 2003. p.197.

KANASHIRO, S. Nitrogênio, fósforo, potássio, cálcio e o crescimento de plântulas de Aechmea blanchatiana
(Baker) L.B. Smith in vitro. 2005. 187f. Tese (Doutorado em Fitotecnia) - Escola Superior de Agricultura "Luiz de Queiroz", Universidade de São Paulo.

KNUDSON, L. A new nutrient solution for the germination of orchid seed. American Orchid Society Bulletin, West Palm Beach, v.14, p.214-217, 1946.

MALAVOLTA, E. et al. Avaliação do estado nutricional das plantas: princípios e aplicações. 2.ed. Piracicaba: Associação Brasileira para Pesquisa da Potassa e do Fosfato, 1997. 319p.

NUNES et al. Efeito de nitrato de cálcio e cloreto de potássio na multiplicação in vitro de porta-enxerto de 'Kobber' In: CONGRESSO BRASILEIRO DE OLERICULTURA, 45; CONGRESSO BRASILEIRO DE FLORICULTURA E PLANTAS ORNAMENTAIS, 15.; CONGRESSO BRASILEIRO DE CULTURA DE TECIDOS DE PLANTAS, 2., 2005, Fortaleza. Anais... Fortaleza: Horticultura Brasileira, 2005. p.598.

PASQUAL, M. Cultura de tecidos vegetais: tecnologia e aplicações - Meios de cultura. Lavras: UFLA/FAEPE, 2001. $74 \mathrm{p}$.

SAS INSTITUTE SAS/ STAT. SAS/GLM. Software: usage and reference version 6.12. Cary, 1990. 501p.

WILLIANS, R.R. Factors determining mineral uptake in vitro. Acta Horticulturae, Wageningen, v.289, p.165-166, 1991.

ZEHLER, E. et al. Sulfato de potássio e Cloreto de potássio: sua influência na produção e na qualidade das plantas cultivadas. Campinas: Fundação Cargill, 1986. 11 p. 